\title{
Protective and Aggravating Effects of Nlrp3 Inflammasome Activation in IBD Models: Influence of Genetic and Environmental Factors
}

\author{
Christian Bauer $^{\mathrm{a}}$ Peter Duewell ${ }^{\mathrm{a}}$ Hans-Anton Lehr ${ }^{\mathrm{b}}$ Stefan Endres ${ }^{\mathrm{c}}$ \\ Max Schnurra \\ ${ }^{a}$ Medizinische Klinik und Poliklinik IV, Klinikum der Universität München, München, Germany; \\ ${ }^{\mathrm{b}}$ Institut Universitaire de Pathologie, Centre Hospitalier Universitaire Vaudois, Lausanne, Switzerland; \\ cAbteilung für Klinische Pharmakologie and Center for Integrated Protein Science Munich (CIPS-M), \\ Medizinische Klinik und Poliklinik IV, Klinikum der Universität München, München, Germany
}

\section{Key Words}

Nlrp3 inflammasome $\cdot$ Caspase-1 1 IL-18 $\cdot$ Experimental colitis

\begin{abstract}
Background: Inflammatory bowel disease (IBD) is characterized by chronic intestinal inflammation due to dysregulation of the mucosal immune system. The cytokines IL-1 $\beta$ and IL-18 appear early in intestinal inflammation and their pro-forms are processed via the caspase-1-activating multiprotein complex, the Nlrp3 inflammasome. Previously, we reported that the uptake of dextran sodium sulfate (DSS) by macrophages activates the NIrp3 inflammasome and that Nlrp3 $3^{-/-}$ mice are protected in the acute DSS colitis model. Of note, other groups have reported opposing effects in regards to DSS susceptibility in $\mathrm{Nlrp3}^{-/}$mice. Recently, mice lacking inflammasomes were found to develop a distinct intestinal microflora. Methods: To reconcile the contradicting observations, we investigated the role of Nlrp3 deficiency in two different IBD models: acute DSS colitis and TNBS (2,4,6-trinitrobenzene sulfonic acid)-induced colitis. In addition, we in-
\end{abstract}

vestigated the impact of the intestinal flora on disease severity by performing cohousing experiments of wild-type and $\mathrm{Nlrp3}^{-/-}$mice, as well as by antibiotic treatment. Results: $\mathrm{Nlrp3}^{-/-}$mice treated with either DSS or TNBS exhibited attenuated colitis and lower mortality. This protective effect correlated with an increased frequency of CD103+ lamina propria dendritic cells expressing a tolerogenic phenotype in $\mathrm{Nlrp}^{-/-}$mice in steady state conditions. Interestingly, after cohousing, Nlrp3 ${ }^{-/-}$mice were as susceptible as wild-type mice, indicating that transmission of endogenous bacterial flora between the two mouse strains might increase susceptibility of $\mathrm{Nlrp3}^{-/-}$mice towards DSS-induced colitis. Accordingly, treatment with antibiotics almost completely prevented colitis in the DSS model. Conclusions: The composition of the intestinal microflora significantly influences disease severity in IBD models comparing wild-type and $\mathrm{NIrp3}^{-/-}$ mice. This observation may - at least in part - explain contradictory results concerning the role of the inflammasome in different labs. Further studies are required to define the role of the Nlrp3 inflammasome in noninflamed mucosa under steady state conditions and in IBD.

Copyright $\odot 2012$ S. Karger AG, Basel

\section{KARGER}

Fax +41613061234

E-Mail karger@karger.ch

www.karger.com (c) 2012 S. Karger AG, Basel

$0257-2753 / 12 / 0307-0082 \$ 38.00 / 0$

Accessible online at:

www.karger.com/ddi
Prof. Max Schnurr

Medizinische Klinik und Poliklinik IV, Klinikum der Universität München Ziemssenstrasse 1

DE-80336 München (Germany)

Tel. +49 895160 5300, E-Mail max.schnurr@med.uni-muenchen.de 


\section{Introduction}

Crohn's disease and ulcerative colitis are inflammatory bowel diseases (IBD) with a chronic, relapsing, and remitting course [1]. The etiology of IBD is incompletely understood. Both genetic and environmental factors mediate the dysregulation of the mucosal immune system in the gastrointestinal tract. Even in healthy conditions, small amounts of bacterial antigen can cross the epithelial barrier that separates the gut lumen from the adjacent mucosa and submucosa. These bacteria or their constituents interact with various immune cells, in particular macrophages and dendritic cells (DC) in the lamina propria. The constant challenge of the mucosal immune system has led to evolutionarily conserved feedback mechanisms protecting the organism from excessive immune responses. Under healthy conditions, these feedback mechanisms create an equilibrium that is known as the mucosal steady state [2]. Danger signals are believed to break this steady state and initiate proinflammatory cascades [3]. Immune responses to such signals must differentiate between the 'harmless' normal intestinal flora and more pathogenic bacteria that need to be 'defeated'. However, even under the conditions of active inflammation, the feedback loops of a healthy organism are preserved and effectively limit the proinflammatory immune response within the lamina propria. There is ample evidence that mutations in defined components of immune signaling cascades predispose to the development of IBD. Dozens of molecular candidates have been identified that contribute to a deregulated phenotype $[4,5]$.

However, it is currently unknown if these deregulated molecular cascades exert their proinflammatory effects in the absence of specific environmental factors or if an initial pathogenic stimulus is needed to initiate the detrimental cascade, eventually leading to IBD. Recently, it was demonstrated that norovirus infection of ATG16L1-deficient mice triggers intestinal inflammation. Genetic factors (ATG16L1), environmental factors (the commensal flora), and danger signals (dextran sodium sulfate (DSS), norovirus infection) were shown to act in concert in order to induce manifest intestinal inflammation. Anti-TNF- $\alpha$ and anti-IFN- $\gamma$ strategies, as well as antibiotic treatment, were able to ameliorate colitis induction [6].

Possibly, shifts in the genetic signature of individuals may exert an influence on the environmental factors themselves (composition of the intestinal bacteria settling in the host from the first days of life - long before disease appears) [7]. Of interest, all these mechanisms pu- tatively affect the interpretation of data of pharmacological intervention studies as well as of gene knockout studies in the field of IBD.

\section{Materials and Methods}

Mice

$\mathrm{Nlrp}^{-1-}$ mice were bred at the University of Munich and used for experiments at ages spanning 8-16 weeks. Age-matched wildtype controls were purchased from Harlan Laboratories (Borchen, Germany). Mice were fed standard mice chow pellets and had access to tap water supplied in bottles. All experiments were approved by the regional animal study committee and are in agreement with the guidelines for the proper use of animals in biomedical research.

\section{Induction of Colitis and Treatment}

DSS colitis was induced with 2\% DSS (MW $40 \mathrm{kDa}$ ) dissolved in drinking water given ad libitum. Control mice were given tap water. To investigate the influence of intestinal flora on the extent of the colitis, Nlrp3 $3^{-/-}$mice and wild-type controls were cohoused in order to assure transfer of intestinal microbiota. Both mouse strains were kept together in cages for 2 weeks before DSS exposure. In addition, treatment with a combination of antibiotics was investigated. Mice received drinking water with or without ampicillin $(1 \mathrm{mg} / \mathrm{ml})$, metronidazole $(1 \mathrm{mg} / \mathrm{ml})$, neomycin $(1 \mathrm{mg} / \mathrm{ml})$, and vancomycin $(0.5 \mathrm{mg} / \mathrm{ml})$. TNBS (2,4,6-trinitrobenzene sulfonic acid) colitis was induced by rectal administration of 2 doses of $2 \mathrm{mg}$ TNBS (Sigma, St. Louis, Mo., USA) in $40 \%$ ethanol, using a vinyl catheter with the opening position $2.5 \mathrm{~cm}$ away from the anus. Administration of the two doses was separated by a 7-day interval. Mice were sacrificed on day 9 for histological analysis.

\section{Clinical Score and Histological Analysis}

A scoring system was used in order to assess diarrhea and the presence of occult or overt blood in the stool. Postmortem, the colon was removed and pieces of colonic tissue were used for histological analysis. Rings of the transverse part of the colon were fixed in $4 \%$ buffered formalin, embedded in paraffin, and stained with hematoxylin and eosin. Histological scoring was performed in a blinded way by a pathologist (H.-A.L.) as described [8]

\section{Ex vivo Analysis of Lamina Propria CD103+ DC}

For isolation of immune cells from the lamina propria, colon sections were cut into small fragments, incubated with EDTA (Sigma-Aldrich, Munich, Germany) and dithiothreitol (SigmaAldrich) in Hanks' balanced salt solution, and passed through a $70-\mu \mathrm{m}$ cell strainer. The suspension of epithelial and subepithelial cells as well as intraepithelial lymphocytes was removed and the remaining lamina propria was collected. After digestion with collagenase D, DNase I, and dispase (Roche, Mannheim, Germany) the suspension was stained with fluorochrome-labeled antibodies against CD11b, CD11c, CD86 (BD Biosciences, Heidelberg, Germany), and CD103 (BioLegend, San Diego, Calif., USA). Fluorescence intensity was analyzed using a FACSCalibur (BD Biosciences, San Diego, Calif., USA). Data analysis was performed using FlowJo software (Tree Star, Ashland, Oreg., USA). 
Statistics

Data are expressed as means \pm SEM. Statistical significance of differences between treatment and control groups was determined by Student's t test. Differences were considered statistically significant at $\mathrm{p}<0.05$.

\section{Results and Discussion}

\section{Role of the Nlrp3 Inflammasome in IBD}

Recently, Nlrp3 has emerged as an important player in the field of inflammatory response. Activation of caspase- 1 was found to be controlled by a cytosolic multiprotein complex termed the inflammasome [9]. Since the original description in 2002, several inflammasome complexes have been described, which differ in their subdomains, including Nlrp1, Nlrp3, Nlrc4, and Aim2. Whereas Nlrp1, Nlrc4, and Aim2 are thought to be primarily involved in recognition of microbial products, the Nlrp3 inflammasome also induces inflammatory responses towards certain sterile stimuli [10]. Diseases such as gout, asbestosis, diabetes, and atherosclerosis are mediated by the Nlrp3 inflammasome [11-13]. The Nlrp3 inflammasome is a multimeric complex consisting of Nlrp3, the adaptor molecule apoptosis-associated speck-like protein (ASC), and procaspase-1. Upon Nlrp3 stimulation, ASC and procaspase-1 are recruited to form a large complex with subsequent autocleavage of procaspase-1. Active caspase- 1 cleaves pro-IL-1 $\beta$ and pro-IL-18 into their biologically active forms, which are then secreted into the extracellular space. This process involves two distinct steps: (1) transcriptional upregulation of Nlrp3 and pro-IL-1 $\beta /$ IL18 via NF- $\kappa B$ or cytokine receptor signaling, and (2) activation of the Nlrp3 inflammasome [14].

Several reports have established an association between the inflammasome pathway and autoinflammatory disorders. Muckle-Wells syndrome, familial cold autoinflammatory synd rome, and neonatal-onset multisystem inflammatory disease are associated with constitutive activation of the Nlrp3 inflammasome due to mutated Nlrp3 [15]. Interestingly, a genetic study has identified single nucleotide polymorphisms likely to reduce Nlrp3 expression that are linked to IBD [16]. Other authors have confirmed a role for Nlrp3 in IBD, but provided evidence that a gain-of-function mutation of Nlrp3 is associated with IBD $[17,18]$. Finally, two recent publications could not corroborate any genetic association between Nlrp3 and IBD $[19,20]$.

These partly contradicting results from cell biology studies as well as human genetics studies have generated great interest in the role of the Nlrp3 inflammasome in murine models of IBD. Recently, our group reported involvement of the Nlrp3 inflammasome in the pathogenesis of DSS-induced colitis [8]. Peritoneal macrophages from Nlrp3 $3^{-/}$mice treated orally with DSS showed significantly reduced secretion of IL-1 $\beta$ in comparison to wild-type mice. Consistent with these data, colon homogenates of $\mathrm{Nlrp}^{-/-}$mice contained lower levels of bioactive IL-1 $\beta$ and other proinflammatory cytokines. In addition, $\mathrm{Nlrp}^{-/-}$mice were less susceptible to the detrimental effects of oral DSS intake. Weight loss, hematochezia, and histology scores, as well as mortality, were significantly reduced in mice lacking the $\mathrm{Nlrp3}^{-/-}$inflammasome [8].

However, other groups have made opposing observations. Two recent publications found a protective effect of the Nlrp3 inflammasome in DSS-induced colitis $[21,22]$. Using bone marrow chimeras, Zaki et al. [22] found that Nlrp3 signaling in nonhematopoietic cells protects against DSS-induced colonic injury. Their study used higher DSS concentrations than ours (4 vs. $2 \%$ ) resulting in faster induction of clinical symptoms. Nevertheless, in the study by Zaki et al. [22] the mice showed a marked resistance to high DSS doses, suggesting that as yet undefined factors contribute to the phenotype of $\mathrm{Nlrp} 3^{-/}$ mice seen in different animal facilities.

These contradictory results are paralleled by findings in caspase-1- and IL-18-deficient mice. Siegmund et al. [23] reported protection of caspase- $1^{-/-}$mice from the deleterious effects of DSS administration and our group found that treatment of mice with the caspase-1 inhibitor pralnacasan ameliorated colonic inflammation [24, 25]. In contrast, a recent study showed that caspase- $1^{-/-}$mice have aggravated colonic inflammation [7]. Moreover, two studies found that treatment with anti-IL-18 antibody or IL-18-binding protein reduced the severity of DSS-induced colitis $[26,27]$. In contrast, IL-18 ${ }^{-/-}$or IL-18 receptor $^{-/-}$mice developed a more severe colitis than wild-type controls, arguing for a protective role of IL-18 in tissue repair [28]. As possible reasons for these opposing results, different DSS batches, varying DSS concentrations, and different mouse strains and age have been discussed. Alternatively, differing intestinal microbiota in wild-type versus caspase- $1^{-/-}$or $\mathrm{IL}-18^{-/-}$mice might have been a confounder; however, no direct evidence was available at that time.

A Dual Role for the Nlrp3 Inflammasome in Epithelial and Mononuclear Cells

Despite the frequent use of the DSS-induced colitis model in IBD research, little is known about the precise 
Fig. 1. Proposed pathophysiological model of DSS-induced colitis. The integrity of intestinal epithelial cells (IEC) is disrupted by direct toxic effects of DSS, allowing bacteria and DSS particles to get into contact with macrophages and DC located in the lamina propria. Bacterial compounds induce NF- $\mathrm{\kappa B}$ or cytokine receptor signaling with transcriptional upregulation of Nlrp3, pro-IL-1 $\beta$, and pro-IL-18 (step 1 of the proposed two-hit theory of DSS action, see text). Uptake of DSS into macrophages and DC activates the Nlrp3 inflammasome, resulting in activation of caspase-1, which in turn cleaves pro-IL- $1 \beta$ and proIL-18 into the biologically active forms (step 2). Proinflammatory cytokines, such as IL-12 and IL-18, induce the activation and differentiation of CD4+ T cells into a Th1 phenotype, entertaining the inflammatory response. In contrast, release of IL18 from IEC may be an important regulatory mechanism, promoting mucosal repair after DSS-induced damage.

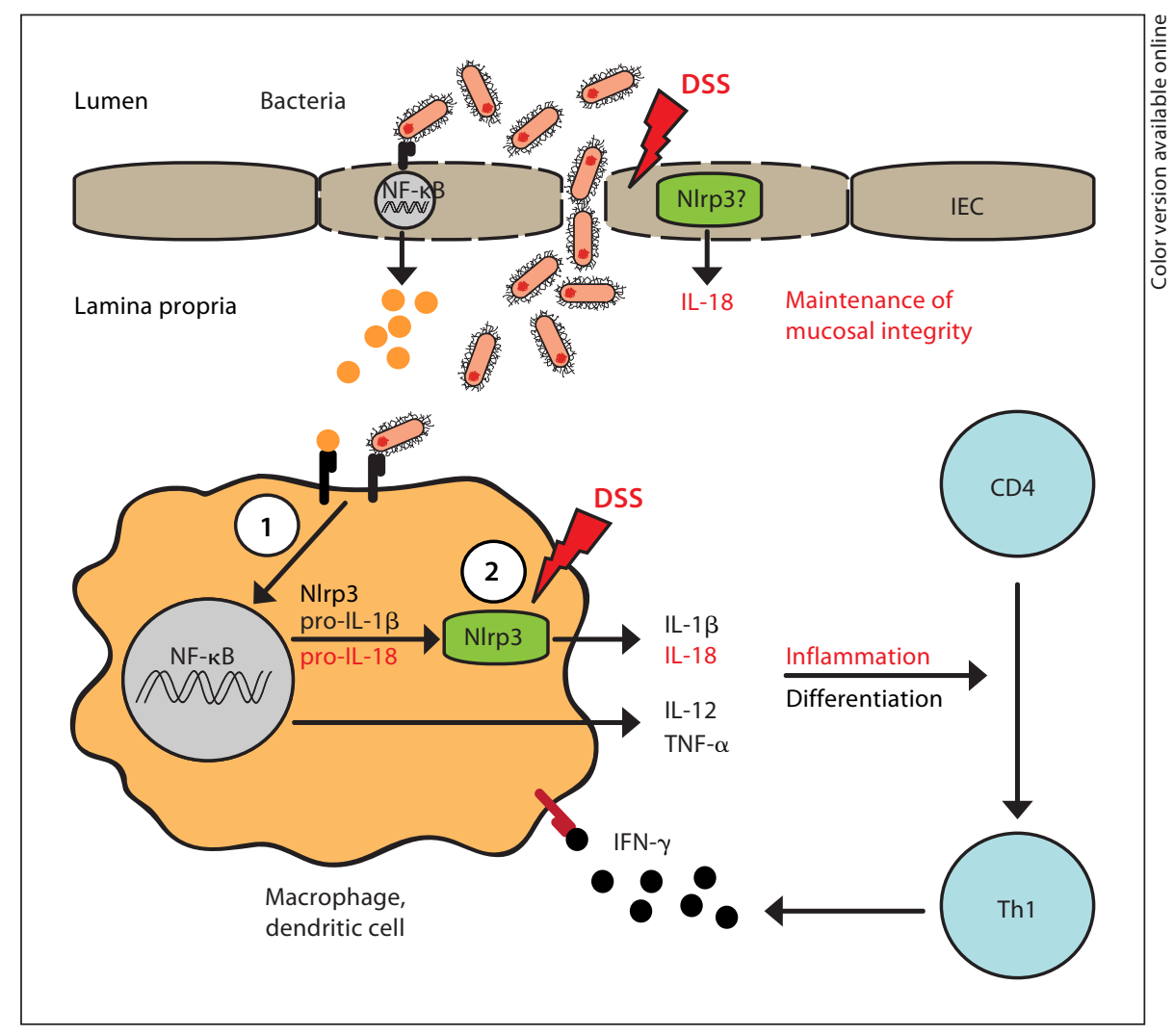

mechanisms by which DSS induces colitis in mice. Certainly, DSS is a toxin, damaging the epithelial barrier, which allows bacteria and microbial components to interact with immune cells located in the lamina propria. Thus, the DSS model is generally viewed as an epithelial damage model suited to investigate wound-healing processes and innate immune responses. In concordance with this view, clinical manifestations of DSS intake do not occur before the fourth or fifth day of DSS administration, along with the appearance of histological hallmarks of epithelial injury.

Other authors have suggested that DSS uptake by lamina propria macrophages initiates an inflammatory process. Araki et al. [29] noted the uptake of orally administered DSS by lamina propria immune cells. Our own data also point towards a direct effect of DSS on macrophages: macrophages primed with LPS and subsequently exposed to DSS secrete high levels of IL-1 $\beta$ and IL-18 in an Nlrp3-, ASC-, and caspase-1-dependent manner [8]. This effect was completely abrogated when the endocytosis of DSS was experimentally blocked. Combining these distinct aspects of DSS action led us to postulate a two-hit hypothesis. First, DSS-induced epithelial damage leads to bacterial translocation into the lamina propria, with subsequent NF- $\kappa \mathrm{B}$ or cytokine receptor signaling in macrophages or DC, and enhanced transcription of Nlrp3, proIL-1 $\beta$, and pro-IL-18 (step 1). Subsequent activation of the Nlrp3 inflammasome by endocytosed DSS induces the cleavage of cytokines into their biologically active forms and their subsequent secretion, initiating and entertaining an inflammatory cascade (step 2; fig. 1). However, other yet to be defined mechanisms in vivo may lead to IL-1 $\beta$ and IL-18 processing independent of the Nlrp3 inflammasome.

\section{Role for the Nlrp3 Inflammasome in the} TNBS-Induced Colitis Model

We previously reported that weight loss, hematochezia, and histology scores, as well as mortality, are significantly reduced in mice lacking the Nlrp3 inflammasome in the acute DSS colitis model [8]. As mentioned before, a putative direct effect of DSS on Nlrp3 inflammasome activation in macrophages and DC has to be considered when trying to understand the exact pathophysiological role of Nlrp3 in IBD. We therefore examined a second model of chemically-induced colitis, the TNBS model, in 

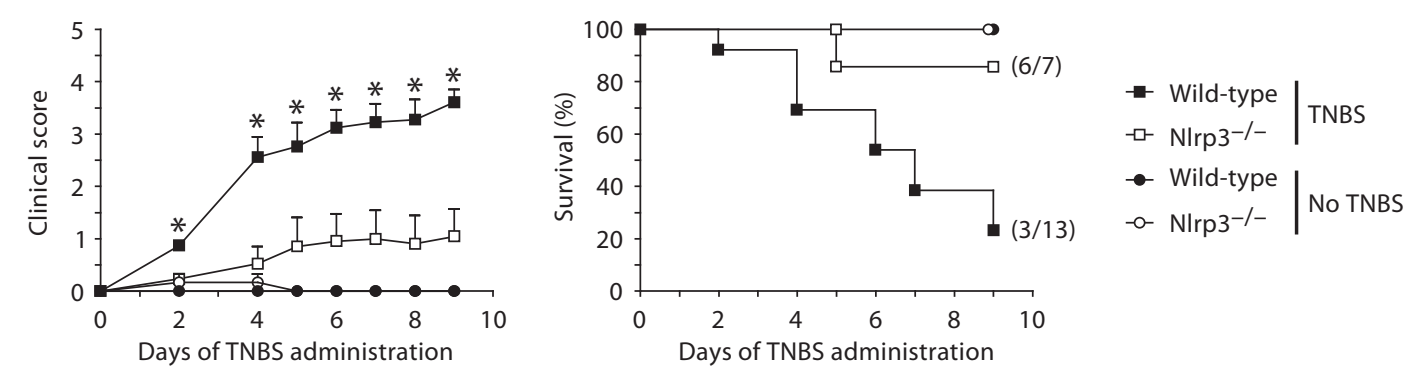

Fig. 2. Nlrp3 deficiency protects mice from TNBS-induced colitis. Nlrp3 $3^{-/}$and wild-type mice were challenged with $2 \%$ TNBS intrarectally. Clinical colitis symptoms and mortality were significantly reduced in Nlrp3 $3^{-/-}$ mice compared to wild-type controls. Data are mean values \pm SEM of at least 7 mice per group. ${ }^{*} \mathrm{p}<0.05$.

which suspension of TNBS in ethanol is administered rectally. TNBS can cross the mucosal barrier and has been described as a T cell-driven model, presumably by acting as a hapten to activate $\mathrm{T}$ cells directly. However, bystander mononuclear cells also appear to be involved in the TNBS-induced immune response [30-32]. After rectal application of TNBS, mice developed severe intestinal inflammation and weight loss within a few days. As observed in the DSS model, clinical disease severity, as assessed by diarrhea, bloody stools, weight loss, and mortality, was significantly reduced in $\mathrm{Nlrp}^{-/-}$mice, indicating that Nlrp3-deficiency may also protect against TNBS challenge (fig. 2).

\section{Effects of Inflammasome-Deficiency on the}

\section{Composition of Intestinal Microflora}

The key for understanding the apparently discrepant results of colitis experiments performed in different laboratories may be found in environmental factors, such as the intestinal microbiota, that can vary between different facilities and mouse strains [33]. Flavell's group [7] has established an elegant model to investigate the role of the intestinal microflora in DSS-induced colitis in inflammasome-deficient mice. $\mathrm{ASC}^{-/-}$and $\mathrm{Nlrp6}^{-/-}$ mice exhibited a higher susceptibility to DSS-induced colitis when compared to wild-type mice. However, cohoused wild-type and $\mathrm{ASC}^{-/-}$or $\mathrm{Nlrp6}^{-/-}$mouse strains were similarly susceptible to DSS challenge, indicating that a 'colitogenic' intestinal flora can be transferred from one strain to the other. Analysis of the fecal microbiota of Nlrp6 ${ }^{-/-}, \mathrm{ASC}^{-/-}$, caspase- ${ }^{-/-}$, and IL- $18^{-/-}$mice versus wild-type mice by $16 \mathrm{~S}$ rRNA-based analysis revealed a higher frequency of Prevotellaceae, which be- long to the phylum Bacteroidetes, in mice lacking the respective components of the inflammasome cascade. Interestingly, abrogation of Prevotellaceae by antibiotics rendered Nlrp6 $6^{-1}$ mice as sensitive to DSS as wild-type mice. The authors concluded from their observations that the differences in DSS susceptibility of wild-type and inflammasome-deficient mice seen by different laboratories might be explained by a specific composition of the intestinal microbiota. In support of this idea is a recently published study, which described a specific role for microbiota in inflammasome-deficient animals in nonalcoholic fatty liver disease and obesity [34]. Thus, interactions between genotype and environmental factors add another level of complexity to IBD that had until now escaped attention in experimental IBD mouse studies.

These exciting data led us to investigate the influence of cohousing wild-type and Nlrp3 $3^{-/-}$mice in the acute DSS colitis model. To assure transfer of intestinal microbiota, both mouse strains were kept together in cages for 2 weeks before receiving 2\% DSS in drinking water. Under these conditions both mouse strains lost weight to the same extent and developed a similar severity of hematochezia, indicating that the susceptibility of wild-type mice towards DSS was transmittable to $\mathrm{Nlrp}^{-/-}$mice. Also, histological analyses of the distal colon showed almost identical inflammatory reactions in the two mouse strains (fig. 3a). In addition, treatment of the mice with a combination of four antibiotics almost completely prevented the detrimental effects of DSS exposure in both mouse strains (fig. 3b). From these findings and reports in the literature $[35,36]$ we conclude that gut microbiota are critical determinants for the severity of DSS-induced 


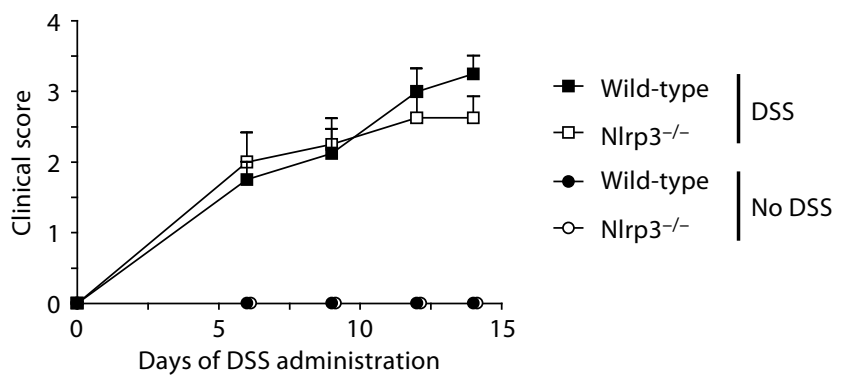

a

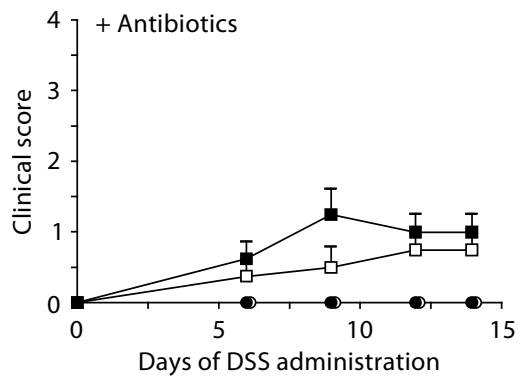

b
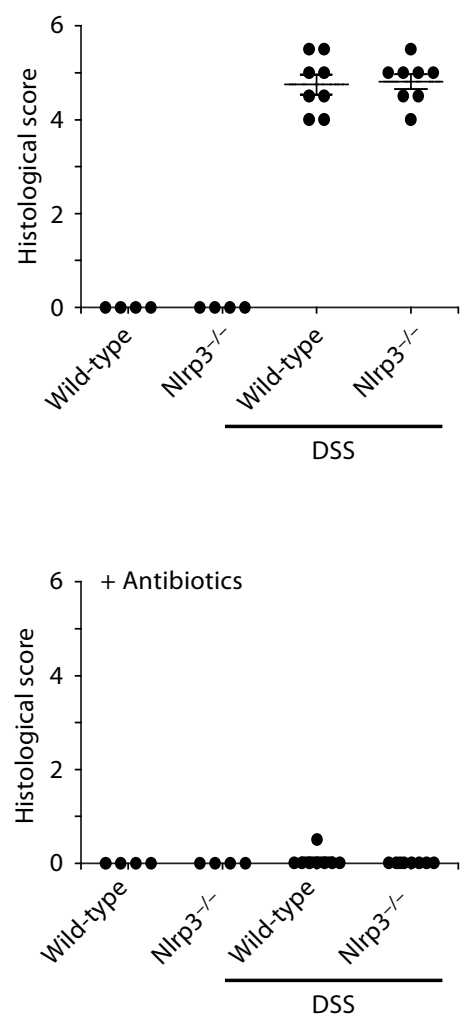

Fig. 3. Influence of cohousing and treatment with antibiotics on DSS-induced colitis in Nlrp3 $3^{-/-}$mice. a Cohousing of wild-type with Nlrp3 $3^{-/-}$mice abrogates the beneficial effect of Nlrp3 deficiency. Nlrp3 $3^{-/}$mice cohoused with wild-type mice exhibit similar levels of weight loss, hematochezia, diarrhea, and histological signs of colitis. b Antibiotic treatment significantly reduces colitis symptoms and histological signs of colitis after DSS exposure. Mean values \pm SEM of 8 mice per group are shown.

colitis and that the influence of genetic factors on the intestinal microbiota has to be considered when comparing knockout mice with wild-type mice in experimental colitis models.

\section{DC in the Lamina Propria of Nlrp3-Deficient Mice Express a Tolerogenic Phenotype}

What further steps are necessary to clarify the role of Nlrp3 in IBD models? The importance of diverse cell types involved in antigen sampling and presentation in the lamina propria in the regulation of the homeostasis of the gut immune system has been appreciated [37]. The precise roles of macrophages and DC in DSS-induced colitis are a matter of ongoing debate, as both proinflammatory and anti-inflammatory effects have been described. Depletion of macrophages/DC with liposomeencapsulated clodronate ameliorated colitis in IL-10- deficient mice, indicating that intestinal mononuclear phagocytes play a proinflammatory role [38]. In turn, selective depletion of CD11c+ DC aggravated DSS-induced colitis, indicating that DC may be protective, e.g. via secretion of anti-inflammatory cytokines such as IL-10 or TGF- $\beta$ [39]. Recently, CD103+ DC have been described as potent inductors of regulatory $\mathrm{T}$ cells in murine colitis models [40]. These tolerogenic DC are believed to represent a mucosal phenotype of DC characterized by upregulation of CD103 upon arrival of monocytic precursors from the blood in the intestine and differentiation into DC $[41,42]$.

The factors that contribute to the tolerogenic environment in the gut are largely unknown, but might putatively include retinoic acid and TGF- $\beta$ produced by intestinal epithelial cells and/or immune cells in the lamina propria [43]. The tolerogenic potential of CD103+ DC appears to 


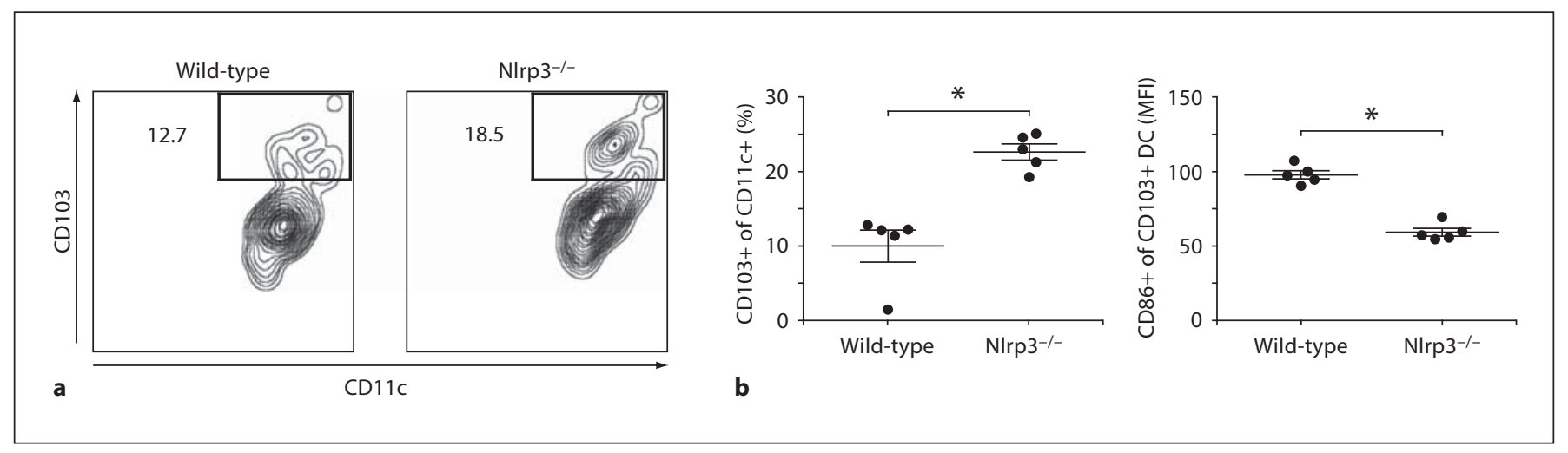

Fig. 4. Nlrp3 $3^{-/-}$mice exhibit an increased frequency of tolerogenic CD103+ DC in intestinal lamina propria and spleen during steady state. a Single cell suspensions of lamina propria cells were stained with fluorochrome-labeled antibodies and analyzed by flow cytometry. No difference in the total number of CD11c+ DCs was observed between Nlrp3 $3^{-/}$mice and wild-type mice (not shown); Nlrp3 $3^{-/-}$mice exhibited a higher frequency of CD103+ CD11c+ DC compared to wild-type mice $(24.7 \pm 8.8$ vs. $14.9 \pm$

be restricted to the steady state [44], while during intestinal inflammation this tolerogenic function appears to be lost [45]. Apparently, an imbalance of the various lamina propria DC subpopulations predisposes to IBD development $[37,46]$. The question remains, which mechanisms guide the transition from steady state to a proinflammatory state in the gastrointestinal tract?

As $\mathrm{Nlrp}^{-/-}$mice were protected against DSS- and TNBS-induced colitis, specifically in the early phase of the disease, we speculated that lamina propria DC of $\mathrm{Nlrp}^{-1-}$ mice might express a more tolerogenic phenotype under steady state conditions. To address this question, we generated single cell suspensions from lymphatic organs and the lamina propria of wild-type and $\mathrm{Nlrp}^{-/-}$mice and stained these with fluorochromelabeled antibodies against CD11b, CD11c, CD86, and CD103 for analysis by flow cytometry. In lymphatic organs as well as in the lamina propria, CD11b+CD11c+ DC demonstrated CD103- and CD103+ subpopulations. We found that the frequency of CD103+ DC amongst all $\mathrm{CD} 11 \mathrm{~b}+\mathrm{CD} 11 \mathrm{c}+$ cells derived from the lamina propria was significantly higher in Nlrp3 ${ }^{-/-}$mice than in wildtype mice (fig. 4a). Similarly, CD103+ DC were more frequent among $\mathrm{CD} 11 \mathrm{~b}+\mathrm{CD} 11 \mathrm{c}+$ cells from the spleens of $\mathrm{Nlrp}^{-/-}$mice than from wild-type mice $(22.7 \pm 1.1 \%$ vs. $10.0 \pm 2.1 \%, \mathrm{p}<0.001)$. We also noted that the total number of CD11b+CD11c+ DC did not differ between $\mathrm{Nlrp}^{-/-}$and wild-type mice. Finally, expression of the
$3.2 \%)$. $\mathbf{b}$ The frequency of splenic CD103+ CD11+ DC was increased in Nlrp $3^{-/-}$mice, whereas the expression of the costimulatory molecule CD86 was significantly reduced, indicative of a tolerogenic DC phenotype. Shown are data from one of two independent experiments with 5 mice per group. Data in $\mathbf{b}$ are individual measurements, as well as mean values \pm SEM of 5 mice. ${ }^{*} \mathrm{p}<0.05$.

costimulatory molecule CD86 was found to be reduced on $\mathrm{CD} 103+\mathrm{DC}$ derived from the spleens of $\mathrm{Nlrp}^{-/-}$mice (fig. 4b). No difference in CD86 expression was observed for CD103- DC (data not shown).

These findings confirm that lamina propria DC in $\mathrm{Nlrp}^{-/-}$mice express a more tolerogenic phenotype, which may account for the reduced susceptibility in chemically induced colitis models. The precise role of the tolerogenic phenotype of lamina propria DC in Nlrp3 $3^{-/-}$ mice in steady state and in inflammatory conditions is the focus of ongoing studies in our laboratory.

\section{Conclusion}

Inflammasome- and caspase-1-regulated processes play a pivotal role in intestinal homeostasis and inflammation. Both protective and detrimental effects of the Nlrp3 inflammasome and IL-18 have been described in murine IBD models. A possible key is compartmentalization of IL-18 processing. While epithelial cell-derived IL18 might exert a protective effect by assuring the maintenance of mucosal integrity, IL-18 produced by lamina propria immune cells, such as macrophages or DC, can trigger a proinflammatory cascade and, hence, contribute to excessive tissue damage in predisposed individuals. However, recent studies have added another layer of complexity. Genetic alterations in components of inflamma- 
somes, including Nlrp3, may bring about changes in intestinal microbiota with potential colitogenic properties. These findings should prompt further research regarding the influence of the gut microflora on the development of IBD with more sophisticated methodology, such as extensive whole genome sequencing ('deep sequencing') of the gut microbiome. In addition, we should be careful when interpreting data from experimental colitis models comparing different mouse strains. Cohousing experiments are a relatively simple way to explore whether differences in microbial composition are the main contributors to a specific phenotype found in knockout mice and should be indispensable for future IBD research.

\section{Acknowledgments}

This work was supported by the Deutsche Forschungsgemeinschaft SCHN 664/3-1 to M.S. and GK 1202 to M.S., P.D. and S.E.

\section{Disclosure Statement}

None of the authors have a financial conflict of interest to declare.

\section{References}

1 Podolsky DK: Inflammatory bowel disease. N Engl J Med 2002;347:417-429.

2 Persson EK, Jaensson E, Agace WW: The diverse ontogeny and function of murine small intestinal dendritic cell/macrophage subsets. Immunobiology 2010;215:692-697.

3 Matzinger P: The danger model: a renewed sense of self. Science 2002;296:301-305.

4 Franke A, Balschun T, Sina C, Ellinghaus D, Hasler R, Mayr G, Albrecht M, Wittig M, Buchert E, Nikolaus S, Gieger C, Wichmann HE, Sventoraityte J, Kupcinskas L, Onnie CM, Gazouli M, Anagnou NP, Strachan D, McArdle WL, Mathew CG, Rutgeerts P, Vermeire S, Vatn MH, Krawczak M, Rosenstiel P, Karlsen TH, Schreiber S: Genome-wide association study for ulcerative colitis identifies risk loci at 7q22 and 22q13 (IL17REL). Nat Genet 2010;42:292-294.

5 Anderson CA, Boucher G, Lees CW, Franke A, D’Amato M, Taylor KD, Lee JC, Goyette P, Imielinski $M$, Latiano A, Lagace C, Scott R, Amininejad L, Bumpstead S, Baidoo L, Baldassano RN, Barclay M, Bayless TM, Brand S, Buning C, Colombel JF, Denson LA, De Vos M, Dubinsky M, Edwards C, Ellinghaus D, Fehrmann RS, Floyd JA, Florin T, Franchimont D, Franke L, Georges M, Glas J, Glazer NL, Guthery SL, Haritunians T, Hayward NK, Hugot JP, Jobin G, Laukens D, Lawrance I, Lemann M, Levine A, Libioulle C, Louis E, McGovern DP, Milla M, Montgomery GW, Morley KI, Mowat C, Ng A, Newman W, Ophoff RA, Papi L, Palmieri O, Peyrin-Biroulet L, Panes J, Phillips A, Prescott NJ, Proctor DD, Roberts R, Russell R, Rutgeerts P, Sanderson J, Sans M, Schumm P, Seibold F, Sharma Y, Simms LA, Seielstad M, Steinhart AH, Targan SR, van den Berg LH, Vatn $M$, Verspaget $H$, Walters $T$, Wijmenga $C$, Wilson DC, Westra HJ, Xavier RJ, Zhao ZZ, Ponsioen CY, Andersen V, Torkvist L, Gazouli M, Anagnou NP, Karlsen TH, Kup- cinskas L, Sventoraityte J, Mansfield JC, Kugathasan S, Silverberg MS, Halfvarson J, Rotter JI, Mathew CG, Griffiths AM, Gearry R, Ahmad T, Brant SR, Chamaillard M, Satsangi J, Cho JH, Schreiber S, Daly MJ, Barrett JC, Parkes M, Annese V, Hakonarson H, Radford-Smith G, Duerr RH, Vermeire S, Weersma RK, Rioux JD: Meta-analysis identifies 29 additional ulcerative colitis risk loci, increasing the number of confirmed associations to 47. Nat Genet 2011;43:246-252.

6 Cadwell K, Patel KK, Maloney NS, Liu TC, $\mathrm{Ng}$ AC, Storer CE, Head RD, Xavier R, Stappenbeck TS, Virgin HW: Virus-plus-susceptibility gene interaction determines Crohn's disease gene Atg16L1 phenotypes in intestine. Cell 2010;141:1135-1145.

7 Elinav E, Strowig T, Kau AL, Henao-Mejia J, Thaiss CA, Booth CJ, Peaper DR, Bertin J, Eisenbarth SC, Gordon JI, Flavell RA: NLRP6 inflammasome regulates colonic microbial ecology and risk for colitis. Cell 2011;145:745-757.

8 Bauer C, Duewell P, Mayer C, Lehr HA, Fitzgerald KA, Dauer M, Tschopp J, Endres S, Latz E, Schnurr M: Colitis induced in mice with dextran sulfate sodium (DSS) is mediated by the NLRP3 inflammasome. Gut 2010;59:1192-1199.

9 Martinon F, Burns K, Tschopp J: The inflammasome: a molecular platform triggering activation of inflammatory caspases and processing of prolL-beta. Mol Cell 2002;10:417426.

10 Rock KL, Latz E, Ontiveros F, Kono H: The sterile inflammatory response. Annu Rev Immunol 2010;28:321-342.

11 Hornung V, Bauernfeind F, Halle A, Samstad EO, Kono H, Rock KL, Fitzgerald KA, Latz E: Silica crystals and aluminum salts activate the NALP3 inflammasome through phagosomal destabilization. Nat Immunol 2008;9: 847-856.
12 Martinon F, Petrilli V, Mayor A, Tardivel A, Tschopp J: Gout-associated uric acid crystals activate the NALP3 inflammasome. Nature 2006;440:237-241.

13 Duewell P, Kono H, Rayner KJ, Sirois CM, Vladimer G, Bauernfeind FG, Abela GS, Franchi L, Nunez G, Schnurr M, Espevik T, Lien E, Fitzgerald KA, Rock KL, Moore KJ, Wright SD, Hornung V, Latz E: NLRP3 inflammasomes are required for atherogenesis and activated by cholesterol crystals. Nature 2010;464:1357-1361.

14 Bauernfeind FG, Horvath G, Stutz A, Alnemri ES, MacDonald K, Speert D, Fernandes-Alnemri T, Wu J, Monks BG, Fitzgerald KA, Hornung V, Latz E: Cutting edge: NF-kappaB activating pattern recognition and cytokine receptors license NLRP3 inflammasome activation by regulating NLRP3 expression. J Immunol 2009; 183:787-791.

15 Goldbach-Mansky R, Dailey NJ, Canna SW, Gelabert A, Jones J, Rubin BI, Kim HJ, Brewer C, Zalewski C, Wiggs E, Hill S, Turner ML, Karp BI, Aksentijevich I, Pucino F, Penzak SR, Haverkamp MH, Stein L, Adams BS, Moore TL, Fuhlbrigge RC, Shaham B, Jarvis JN, O’Neil K, Vehe RK, Beitz LO, Gardner G, Hannan WP, Warren RW, Horn W, Cole JL, Paul SM, Hawkins PN, Pham TH, Snyder C, Wesley RA, Hoffmann SC, Holland SM, Butman JA, Kastner DL: Neonatal-onset multisystem inflammatory disease responsive to interleukin-1beta inhibition. N Engl J Med 2006;355:581-592.

16 Villani AC, Lemire M, Fortin G, Louis E, Silverberg MS, Collette C, Baba N, Libioulle C, Belaiche J, Bitton A, Gaudet D, Cohen A, Langelier D, Fortin PR, Wither JE, Sarfati M, Rutgeerts P, Rioux JD, Vermeire S, Hudson TJ, Franchimont D: Common variants in the NLRP3 region contribute to Crohn's disease susceptibility. Nat Genet 2009;41:71-76. 
17 Schoultz I, Verma D, Halfvarsson J, Torkvist L, Fredrikson M, Sjoqvist U, Lordal M, Tysk C, Lerm M, Soderkvist P, Soderholm JD: Combined polymorphisms in genes encoding the inflammasome components NALP3 and CARD8 confer susceptibility to Crohn's disease in Swedish men. Am J Gastroenterol 2009;104:1180-1188.

18 Verma D, Lerm M, Blomgran Julinder R, Eriksson P, Soderkvist P, Sarndahl E: Gene polymorphisms in the NALP3 inflammasome are associated with interleukin-1 production and severe inflammation: relation to common inflammatory diseases? Arthritis Rheum 2008:58:888-894.

19 Lewis GJ, Massey DC, Zhang H, Bredin F, Tremelling M, Lee JC, Berzuini C, Parkes M: Genetic association between NLRP3 variants and Crohn's disease does not replicate in a large UK panel. Inflamm Bowel Dis 2011; 17:1387-1391.

20 Yang SK, Kim H, Hong M, Lim J, Choi E, Ye $\mathrm{BD}$, Park SK, Song K: Association of CARD8 with inflammatory bowel disease in Koreans. J Hum Genet 2011;56:217-223.

21 Dupaul-Chicoine J, Yeretssian G, Doiron K, Bergstrom KS, McIntire CR, LeBlanc PM, Meunier C, Turbide C, Gros P, Beauchemin N, Vallance BA, Saleh M: Control of intestinal homeostasis, colitis, and colitis-associated colorectal cancer by the inflammatory caspases. Immunity 2010;32:367-378.

22 Zaki MH, Boyd KL, Vogel P, Kastan MB, Lamkanfi M, Kanneganti TD: The NLRP3 inflammasome protects against loss of epithelial integrity and mortality during experimental colitis. Immunity 2010;32:379-391.

23 Siegmund B, Lehr HA, Fantuzzi G, Dinarello CA: IL-1 beta-converting enzyme (caspase-1) in intestinal inflammation. Proc Natl Acad Sci USA 2001;98:13249-13254.

24 Loher F, Bauer C, Landauer N, Schmall K, Siegmund B, Lehr HA, Dauer M, Schoenharting M, Endres S, Eigler A: The interleukin-1 beta-converting enzyme inhibitor pralnacasan reduces dextran sulfate sodium-induced murine colitis and Thelper $1 \mathrm{~T}$ cell activation. J Pharmacol Exp Ther 2004; 308:583-590.

25 Bauer C, Loher F, Dauer M, Mayer C, Lehr HA, Schonharting M, Hallwachs R, Endres $S$, Eigler A: The ICE inhibitor pralnacasan prevents DSS-induced colitis in C57BL/6 mice and suppresses IP-10 mRNA but not TNF-alpha mRNA expression. Dig Dis Sci 2007;52:1642-1652.
26 Siegmund B, Fantuzzi G, Rieder F, Gamboni-Robertson F, Lehr HA, Hartmann G, Dinarello CA, Endres S, Eigler A: Neutralization of interleukin-18 reduces severity in murine colitis and intestinal IFN-gamma and TNF-alpha production. Am J Physiol Regul Integr Comp Physiol 2001;281:R1264R1273.

27 Sivakumar PV, Westrich GM, Kanaly S, Garka K, Born TL, Derry JM, Viney JL: Interleukin 18 is a primary mediator of the inflammation associated with dextran sulphate sodium induced colitis: blocking interleukin 18 attenuates intestinal damage. Gut 2002; 50:812-820.

28 Takagi H, Kanai T, Okazawa A, Kishi Y, Sato $\mathrm{T}$, Takaishi $\mathrm{H}$, Inoue $\mathrm{N}$, Ogata $\mathrm{H}$, Iwao $\mathrm{Y}$, Hoshino K, Takeda K, Akira S, Watanabe M, Ishii $\mathrm{H}, \mathrm{Hibi} \mathrm{T}$ : Contrasting action of IL-12 and IL-18 in the development of dextran sodium sulphate colitis in mice. Scand J Gastroenterol 2003;38:837-844.

29 Araki Y, Andoh A, Fujiyama Y, Bamba T: Development of dextran sulphate sodium-induced experimental colitis is suppressed in genetically mast cell-deficient Ws/Ws rats. Clin Exp Immunol 2000;119:264-269.

30 Alex P, Zachos NC, Nguyen T, Gonzales L, Chen TE, Conklin LS, Centola M, Li X: Distinct cytokine patterns identified from multiplex profiles of murine DSS and TNBS-induced colitis. Inflamm Bowel Dis 2009;15: 341-352.

31 Palmen MJ, Dieleman LA, van der Ende MB, Uyterlinde A, Pena AS, Meuwissen SG, van Rees EP: Non-lymphoid and lymphoid cells in acute, chronic and relapsing experimental colitis. Clin Exp Immunol 1995;99:226-232.

32 Palmen MJ, Dijkstra CD, van der Ende MB, Pena AS, van Rees EP: Anti-CD11b/CD18 antibodies reduce inflammation in acute colitis in rats. Clin Exp Immunol 1995;101: 351-356.

33 Carvalho FA, Nalbantoglu I, Ortega-Fernandez S, Aitken JD, Su Y, Koren O, Walters WA, Knight R, Ley RE, Vijay-Kumar M, Gewirtz AT: Interleukin-1beta (IL-1beta) promotes susceptibility of Toll-like receptor 5 (TLR5) deficient mice to colitis. Gut 2012;61:373384.

34 Henao-Mejia J, Elinav E, Jin C, Hao L, Mehal WZ, Strowig T, Thaiss CA, Kau AL, Eisenbarth SC, Jurczak MJ, Camporez JP, Shulman GI, Gordon JI, Hoffman HM, Flavell RA: Inflammasome-mediated dysbiosis regulates progression of NAFLD and obesity. Nature 2012;482:179-185.

35 Hoentjen F, Harmsen HJ, Braat H, Torrice CD, Mann BA, Sartor RB, Dieleman LA: Antibiotics with a selective aerobic or anaerobic spectrum have different therapeutic activities in various regions of the colon in interleukin 10 gene deficient mice. Gut 2003;52: 1721-1727.
36 Rath HC, Schultz M, Freitag R, Dieleman LA, Li F, Linde HJ, Scholmerich J, Sartor RB: Different subsets of enteric bacteria induce and perpetuate experimental colitis in rats and mice. Infect Immun 2001;69:2277-2285.

37 Iliev ID, Mileti E, Matteoli G, Chieppa M, Rescigno M: Intestinal epithelial cells promote colitis-protective regulatory $\mathrm{T}$-cell differentiation through dendritic cell conditioning. Mucosal Immunol 2009;2:340-350.

38 Watanabe N, Ikuta K, Okazaki K, Nakase H, Tabata Y, Matsuura M, Tamaki H, Kawanami C, Honjo T, Chiba T: Elimination of local macrophages in intestine prevents chronic colitis in interleukin-10-deficient mice. Dig Dis Sci 2003;48:408-414.

39 Qualls JE, Tuna H, Kaplan AM, Cohen DA: Suppression of experimental colitis in mice by CD11c+ dendritic cells. Inflamm Bowel Dis 2009;15:236-247.

40 Varol C, Vallon-Eberhard A, Elinav E, Aychek T, Shapira Y, Luche H, Fehling HJ, Hardt WD, Shakhar G, Jung S: Intestinal lamina propria dendritic cell subsets have different origin and functions. Immunity 2009;31:502-512.

41 Annacker O, Coombes JL, Malmstrom V, Uhlig HH, Bourne T, Johansson-Lindbom B, Agace WW, Parker CM, Powrie F: Essential role for CD103 in the T cell-mediated regulation of experimental colitis. J Exp Med 2005; 202:1051-1061.

42 Coombes JL, Powrie F: Dendritic cells in intestinal immune regulation. Nat Rev Immunol 2008;8:435-446.

43 Wada Y, Hisamatsu T, Kamada N, Okamoto S, Hibi T: Retinoic acid contributes to the induction of IL-12-hypoproducing dendritic cells. Inflamm Bowel Dis 2009;15:15481556.

44 Hofmann C, Dunger N, Grunwald N, Hammerling GJ, Hoffmann P, Scholmerich J, Falk $\mathrm{W}$, Obermeier F: T cell-dependent protective effects of CpG motifs of bacterial DNA in experimental colitis are mediated by CD11c+ dendritic cells. Gut 2010;59:1347-1354.

45 Laffont S, Siddiqui KR, Powrie F: Intestinal inflammation abrogates the tolerogenic properties of MLN CD103+ dendritic cells. Eur J Immunol;40:1877-1883.

46 Bogunovic M, Ginhoux F, Helft J, Shang L, Hashimoto D, Greter M, Liu K, Jakubzick C, Ingersoll MA, Leboeuf M, Stanley ER, Nussenzweig M, Lira SA, Randolph GJ, Merad M: Origin of the lamina propria dendritic cell network. Immunity 2009;31:513-525. 